\title{
Correspondence
}

Correspondents should note that space is limited and shorter letters have a greater chance of publication. The Editors reserve the right to cut letters and also to eliminate multitudinous references. Please try to be concise, strictly relevant and interesting to the reader.

\section{SMOKING PROFILES OF PATIENTS ADMITTED FOR NEUROSIS}

DEAR SiR,

In their paper (Journal, July 1981, 139, 43-6) Salmons and Sims said that our 1971 study (Eastwood and Trevelyan), which found that smoking and neurotic illness were unrelated, was unconvincing as all psychiatric disorders were grouped, and we did not measure neuroticism. This brief dismissal ignored the facts that the study was undertaken on general practice patients using a well-known standardized clinical interview schedule (Goldberg et al, 1970). The great majority of psychiatric illness in the community is of a neurotic nature and of our sample, 95 per cent indeed suffered from neurotic illness. Since the frequency of smoking in the general population is at least twice that of the prevalence of psychiatric disorder, cultural factors must play a paramount role. Furthermore, smoking is increasing amongst the young while the greatest prevalence of neurotic illness lies amongst the middle aged. Where a reduction in smoking behaviour has taken place, amongst middleaged men, it is highly improbable that it has been due to their losing a neurotic illness, but more likely peer pressure and prohibitive taxation.

The deduction that Salmon and Sims made from their selected hospital sample, that "community health strategies for reducing cigarette dependence should take neuroticism into account", seems dubious and, indeed, is based upon weak data. Their hypotheses are reported as though supported and yet only some subcomparisons are significant and often only at the 5 per cent level. Furthermore the chi-square test is used when sometimes cell size is less than five. Examination of Table III shows that the only significant difference between contrast groups with respect to age at starting to smoke was due to the disproportionately small number of neurotics in the older group. Combining the age group figures for males shows that approximately equal proportions of the samples had started smoking by age 30 . When the raw data in Table VI are converted to percentages, it is found that 141 per cent of surgical smokers and 122 per cent of neurotic smokers were found to inhale deeply(!).
This paper does not seem to belie the final conclusion of our earlier paper which was that "the excuse that smoking is a panacea for neuroticism does not seem tenable for the population as a whole".

University of Toronto, M. R. EASTWOOD

Clarke Institute of Psychiatry, 250 College Street, Toronto MST 1 R8

\section{References}

Eastwood, M. R. \& Trevelyan, M. H. (1971) Smoking and neurotic illness. The Lancet, $i, 107-8$.

Goldberg, D. P., CoOper, B., Eastwood, M. R., KedWARD, H. B. \& SHEPHERD, M. (1970) A standardized psychiatric interview for use in community surveys. British Journal of Preventive and Social Medicine, 24, 18-23.

\section{DIAGONAL ELECTROCONVULSIVE THERAPY DEAR SIR,}

Recent studies on the efficacy of unilateral and bilateral electroconvulsive therapy (ECT) in the treatment of depression have not produced unanimous results. We wondered if a diagonal electrode placement (left fronto-right occipital), by directly activating both hemispheres whilst avoiding the temporoparietal region, might produce the therapeutic efficacy of bilateral ECT with the memory impairment of unilateral ECT.

We designed a study to look at this possibility but abandoned it when the first patient reacted badly to the treatment. The patient was a 49-year-old right handed lady presenting with an agitated depression. The anaesthetic given was methohexitone sodium with suxamethonium as muscle relaxant and $0.6 \mathrm{mg}$ atropine. The machine used was an Ectron Mark IV producing a sinusoidal uniphasic wave form and delivering approximately 30-40 joules. Psychological testing included parts of the Moyra Williams and Wechsler memory scales and the Klove Matthews grooved pegboard test.

All measures showed a marked impairment following the first diagonal ECT which had mostly 